\title{
Clinicopathological Features and Survival Data of Localized Renal Masses in Young Adults
}

\author{
Rahmi Aslan*, Kerem Taken, Recep Eryılmaz
}

\begin{abstract}
Purpose: Renal tumors are rarely seen in young adults. In this study, was aimed to report the data of 18-40 years old patients with Renal Cell Carcinoma (RCC) whom we operated. Material and Method: We retrospectively reviewed the data of patients between the ages of 18 and 40 years old patients who have renal masses. All patients were evaluated with chest X-ray, Computed tomography (CT) and/or MRI. Radical or partial nephrectomy was performed for clinical localized masses with malignancy suspicion. Clinicopathological features and survival data of all the patients were recorded. In the follow-up protocol routine blood tests, chest X-ray and abdominal CT were used. Results: A total of 42 patients, [22 (52.4\%) male and $20(47.6 \%)$ female], with a mean age of 34.48 (range 18 to 40 ) were included in the study. Of these, $32(\% 76)$ had RCC and $10(24 \%)$ had benign pathologies. Female patients had more benign pathology (35\% vs $13.6 \%)$. The most commonly subtype of RCC $(\mathrm{n}=22 \% 69)$ was clear cell RCC (cRCC), while the most common benign mass was oncocytoma $(n=4 \% 40)$. At the mean follow-up period of 42.34 months, overall survival rate was found to be $93.8 \%$. Conclusion: Young adults with localized renal mass have benign pathology in a considerable rate. All of the malign masses in this population have low Furhman grade (1 or 2).
\end{abstract}

Keywords: Localized renal mass- renal cell carcinoma- young adults

Asian Pac J Cancer Prev, 19 (11), 3233-3236

\section{Introduction}

While RCC is the 8th most commonly diagnosed primary cancer among all adult tumors, it is in 3rd place among all urinary system tumors. Moreover, it the most lethal urinary system tumor (Landis et al., 1999). Approximately $85-90 \%$ of RCCs are parenchymal solid tumors (Gunes et al., 2012). It is seen most frequently in the 7 th decade. In young adult patients under 40 years it is seen in a very low ratio (3-7\%) (Denzinger et al., 2007). Renal tumors at a younger age can be seen as secondary to hereditary syndromes or as sporadic tumors due to undiagnosed gene mutations (Daugherty et al., 2015). It is thought that kidney tumors seen in young adults are different from those seen in older ages. Particularly, it has been claimed that the tumor characteristics, recurrence interval, and treatment response differ from each other (Denzinger et al., 2007; Thompson et al., 2008). In the literature, published data about young adult kidney tumors are contradictory. Some studies have reported that RCC has negative histological features in young adults, but the others have reported it has more favorable histological subtypes and pathologic features than in older patients (Sánchez et al., 2004; Taccoen et al., 2007; Jung et al., 2009).

In the present study, we aimed to report clinicopathological features and survival data of the patients with renal tumors between the age 18-40 years.

\section{Materials and Methods}

Between 2010-2017 a total of 482 patients underwent partial or radical nephrectomy for renal masses at the Department of Urology of the Van Yuzunci Yil University. Of these, 45 patients between the age 18-40 years included the study. Two patients who had clinical stage 3-4 renal tumor and familial RCC syndromes were excluded from the study. One patient who had missing data during follow up period were also excluded. Remaning 42 patients were further evaluated. For all the tumors smaller than $4 \mathrm{~cm}$ were performed partial nephrectomy; the tumors sized 4-7 cm were performed partial nephrectomy if it is technically feasible. The tumors larger than $7 \mathrm{~cm}$ were performed radical nephrectomy. All patients were evaluated preoperatively by physical examination, labaratory studies, ultrasonography, chest x-ray and computed tomography (CT). A Magnetic resonance imaging (MRI) was performed in the case of renal dysfunction or contrast allergy. The patients who had suspicious malignancy finding on imaging underwent surgery. As the surgical procedure, partial nephrectomy (open/ laparoscopic) or radical nephrectomy (open/laparoscopic) were performed. The postoperative follow-up protocol was adopted according to the European Association of Urology 
guideline. The follow-up time was calculated as the time from the surgery to the death or the last follow-up. In pathological examination, tumor stage was evaluated according to the 2002 TNM classification and Furhman grading system was used for nuclear evaluation. The disease-free survival (DFS) and overall survival (OS) were used as survival data.

\section{Statistical analysis}

Data were analyzed by using Statistical Package for the Social Sciences software package version 20 (SPSS Inc., Chicago, IL, USA). Quantitative data were expressed as mean and range values; categorical data were expressed with frequency (n) and percentages (\%). The data were analyzed at 95\% confidence level and the threshold for statistical significance was accepted as $\mathrm{p}<0.05$ for all analyses.

\section{Results}

42 (22 male and 20 female) patients were included in the study. The mean diagnose age was 34 year (range: 18-40). All of the patients had unilateral mass. Majority of the patients (79\%) were detected incidentally. The majority of the patients $(79 \%)$ had solid mass. The mean mass sizes were $5.11 \mathrm{~cm}$ (range; 2-16) and $5,60 \mathrm{~cm}$ (range; $3-10$ ) in malign tumors and in benign tumors, respectively. None of the patients had lymph node positivity or metastases (Table 1).

Radical nephrectomy was applied to 26 patients (61.9\%); partial nephrectomy was applied to $16(38.1 \%)$ patients. In all patients with partial nephrectomy, the size of the mass was less than $7 \mathrm{~cm}$ (mean $3.65 \mathrm{~cm})$. In patients who underwent radical nephrectomy, $20(77 \%)$ patients had a mass of $4-7 \mathrm{~cm}$ mass; 6 patients $(23 \%)$ had a mass larger than $7 \mathrm{~cm}$. Malignant pathology was found in 18 patients $(69 \%)$, benign in 8 patients $(31 \%)$ who underwent radical nephrectomy and Malignant pathology was

Table1. Patient Characteristics and Mass Features

\begin{tabular}{lc}
\hline Mean Age (years) & $34(18-40)$ \\
Gender & \\
Females, total, n (\%) & $20(47,6)$ \\
Females with benign tumors, n (\%) & $7(39)$ \\
Males, total, n (\%) & $22(52,4)$ \\
Males with benign tumors, n (\%) & $3(12,5)$ \\
Diagnosis & \\
İnsidental, $(\%)$ & $80 \%$ \\
Symptomatic n $(\%)$ & $20 \%$ \\
Tumor size & $8(\% 19)$ \\
T1a $(<4 \mathrm{~cm})$ & $28(\% 67)$ \\
T1b $(4-7 \mathrm{~cm})$ & $4(\% 9)$ \\
T2a $(7-10 \mathrm{~cm})$ & $2(\% 5)$ \\
T2b $(>10 \mathrm{~cm})$ & \\
Tumor nature & $33(79)$ \\
Solit, $\mathrm{n}(\%)$ & $9(21)$ \\
Kisttik, $\mathrm{n}(\%)$ &
\end{tabular}

Table 2. Surgical Method According to Tumor Stage

\begin{tabular}{lcccc}
\hline & $\begin{array}{c}\text { Partial } \\
\text { nephrectomy } \\
\mathrm{n}(\%)\end{array}$ & $\begin{array}{c}\text { Radical } \\
\text { nephrectomy } \\
\mathrm{n}(\%)\end{array}$ & $\begin{array}{c}\text { Benign, } \\
\mathrm{n}(\%)\end{array}$ & $\begin{array}{c}\text { Malign, } \\
\mathrm{n}(\%)\end{array}$ \\
\hline $\mathrm{T} 1 \mathrm{a}(<4 \mathrm{~cm})$ & $7(17)$ & $1(2)$ & $2(5)$ & $6(14)$ \\
$\mathrm{T} 1 \mathrm{~b}(4-7 \mathrm{~cm})$ & $9(21)$ & $19(45)$ & $6(14)$ & $22(52)$ \\
$\mathrm{T} 2 \mathrm{a}(7-10 \mathrm{~cm})$ & - & $4(10)$ & $2(5)$ & $2(5)$ \\
$\mathrm{T} 2 \mathrm{~b}(>10 \mathrm{~cm})$ & - & $2(5)$ & - & $2(5)$ \\
\hline
\end{tabular}

detected in $14(87.5 \%)$ benign in 2 of the patients who underwent partial nephrectomy (12.5\%) (Table 2).

$32(76 \%)$ of 42 patients were reported as RCC. Of these, $22(69 \%)$ were clear cell tumors, $7(22 \%)$ were papillary cell tumors, $2(6 \%)$ were chromophobe and 1 patient was mixed type (papillary / clear cell) tumors. Eleven of these tumors (34\%) were Fuhrman grade-1; 17 (53\%) were reported as Fuhrman grade-2 and none of the patients had Fuhrman grade 3-4 tumors (Table 3).

Four of the tumors reported to be benign were determined to be Oncocytomas $(40 \%), 3$ were Angiomyolipomas (30\%), 2 were hydatic cyst (20\%) and 1 was xanthogranulomatous pyelonephritis (Table 4). Seven $(70 \%)$ of the patients with benign pathology were female and $3(30 \%)$ were male. However, this difference was not found to be statistically significant ( $p>0.05)$. Benign pathologies were reported in 7 of 20 women $(35 \%)$ and in 3 of 26 male patients $(13,6 \%)(p<0,05)$.

During the mean follow-up period of 42.34 months (range 2-84 months), none of the patients undergoing partial nephrectomy had local recurrence or distant metastasis. One patient who underwent radical radical nephrectomy had local recurrence and distant metastases

Table 3. Pathological Features

\begin{tabular}{lc}
\hline & $\mathrm{n}(\%)$ \\
\hline Benign, total & $10(24)$ \\
Oncocytoma & $4(40)$ \\
Angiomyolipoma & $3(30)$ \\
Hydatid cyst & $2(20)$ \\
XPN & $1(10)$ \\
Malign, total & $32(76)$ \\
Clear cell carcinoma & $22(69)$ \\
Papillary cell carcinoma & $7(22)$ \\
Chromophobe-cell carcinoma & $2(6)$ \\
Mix type & $1(3)$ \\
Furhman grading system & $\mathrm{n}(\%)$ \\
Grade-1 & $11(34)$ \\
Grade -2 & $17(53)$ \\
Grade -3 & 0 \\
Grade -4 & 0 \\
\hline
\end{tabular}

Table 4. Follow-up and Survival Data

\begin{tabular}{lc}
\hline Follow-up time & 42.34 (range 2-84 months \\
\hline DFS & $87.5 \%$ \\
OS & $93.8 \%$ \\
\hline
\end{tabular}


while 3 patients had distant metastases. Two of these patients were dead. Overall survival rate was 93.8\%; disease-free survival rate was calculated as $87.5 \%$ (Table 4).

\section{Discussion}

In recent years, the incidence of clinically localized renal masses has increased due to improvements in radiological imaging systems (Smith et al., 1989). Despite technological developments it is not possible to distinguish between benign and malignant masses radiologically. In particular, it is not always possible to definitively diagnose benign masses such as focal xanthogranulomatous pyelonephritis, oncocytoma, chronic pyelonephritis and angiomyolipoma before surgery (Remzi et al., 2007). In the literature, of the patients operated with RCC suspicion has been reported to be benign pathologies in $14 \%-21 \%$ of cases (Frank et al., 2003; Thompson et al., 2009). Angiomyolipomas, oncocytomas, adenomas and simple cysts are the most common of these benign lesions. (Duchene et al., 2003; Licht et al., 1995 ). The studies mentioned are related to general populations. In the young adult patient population, the proportion of bening pathologies was reported by Mohsin et al., (2012) as 11\%, Y1k1lmaz et al., (2015) as $16 \%$, Eggener et al., (2004) as 20.2\%. In these studies, benign pathologies such as angiomyolipoma, oncocytoma, simple cyst, hidatic cyst, pyelonephritis and schwannoma were determined at different rates. In our study, benign pathologies were detected in $24 \%$ of patients who were operated due to clinically localized renal masses between 18 and 40 years of age. This rate may be considered as high compared to the literature.

It is known that most of the renal masses in young patients are RCC. Earlier studies have shown that kidney masses are approximately $80 \%$ malignant; more than 95\% of them were found to have RCC (Y1k1lmaz et al., 2015; Eggener et al., 2004). Kang et al., (2016) reported that $82 \%$ of RCCs in young adults are clear cell RCC, $6 \%$ are papillary RCC, and 7\% are chromophobe-cell RCC, and $90 \%$ of these tumors are T1-2. In another study, $69.5 \%$ of malignant masses were reported to be clear cell, $9 \%$ to papillary cell and 2\% to chromophobe cell carcinoma (Mohsin et al., 2012). In addition to this, there are studies that reported chromophobe cell carcinoma rates higher than $10 \%$ in the literature (Lopez et al., 2010; Renshaw et al., 1999). In our study, the most common clear cell carcinoma and at least chromophobe cell carcinoma were determined as similar to the literature.

In studies evaluating the relationship between mass size and histopathology, it was reported that the entire benign masses were smaller than $7 \mathrm{~cm}$ (Landis et al., 1999; Duchene et al., 2003). In our study, it was determined that $20 \%$ of benign masses were larger than $7 \mathrm{~cm}$, while no significant difference was found between benign and malignant mean mass sizes. This suggests that benign masses larger than $7 \mathrm{~cm}$ can be seen in patients aged 18-40 years. Only 2 patients in our series were diagnosed with malignant mass larger than $10 \mathrm{~cm}$ and both were reported as chromophobe cell carcinoma.

Studies in relation to gender and histopathology have reported that benign pathologies are seen at high rates in young females. Y1k1lmaz et al., (2015) reported that $40 \%$ of young females had benign pathologies, while in males this rate was reported as $4 \%(\mathrm{p}<0.05)$. Similarly, Eggener et al., (2004) reported benign pathology in $36 \%$ of young females and $9.5 \%$ in males. It is suggested that nephron sparing surgery should be preferred to young women because of these high benign mass rate (Y1k1lmaz et al., 2015; Eggener et al., 2004). In our study, benign pathologies were detected in $35 \%$ of the young women and in $13,6 \%$ of the young males and this difference was statistically significant $(\mathrm{p}<0,05)$.

In RCC patients, grade of tumor is the most important parameter affecting survival (Golimbu et al., 1986; Thrasher et al., 1993). Mohsin et al., (2012) reported survival rates of 1 year and 5 years for stage-1 RCC patients below 40 years of age in $98 \%$ and $84 \%$, respectively, whereas in stage-3 RCC patients, these rates were reported as $62 \%$ and $50 \%$, respectively. In another study, 5-year survival rate for stage- 1 tumors was reported as $88 \%$ in patients younger than 40 years (Abou El Fettouh et al., 2002). In our study, mean survival was about $90 \%$ over 3.5 years of follow-up. Another important prognostic factor for RCC is the Fuhrman grading system. Prognosis of Fuhrman grade 1-2 tumors are known to be better than grade 3-4 (Gudhjartsson et al., 2005). Fuhrman grade 3-4 was not detected in our series. therefore, it is thought that RCC has better prognosis in this age group.

The retrospective nature of our study, the low number of patients and the lack of comparisons with elderly patients can be regarded as main limitation of our study. On the other hand, the study will contribute to the literature because this study is focused on clinically localized renal masses of 18-40 years of age with restricted data.

In conclusion, young adults with localized renal mass have benign pathology in a considerable rate. Moreover, all of the malign masses in this population have low Furhman grade (1 or 2). So, nephron sparing surgery should be more preferred over radical nephrectomy for localized renal mass in young adults.

\section{References}

Abou El Fettouh HI, Cherullo EE, et al (2002) Sporadic renal cell carcinoma in young adults: presentation, treatment, and outcome. Urology, 60, 806-10.

Daugherty M, Bratslavsky G (2015) Renal cell carcinoma in young patients: A review of recent literature. Curr Urol Rep, 16, 1-6.

Denzinger S, Otto W, Burger M, et al (2007). Sporadic renal cell carcinoma in young and elderly patients: are there different clinicopathological features and disease specific survival rates?. World J Surg Oncol, 5, 16-22

Duchene DA, Lotan Y, Cadeddu JA, Sagalowsky AI, Koeneman KS (2003). Histopathology of surgically managed renal tumors: analysis of a contemporary series. Urology, 62, 827-3.

Eggener SE, Rubenstein JN, Smith ND, et al (2004). Renal tumors in young adults. $J$ Urol, 171, 106- 10. 
Frank I, Blute ML, Cheville JC, et al (2003). Solid renal tumors: an analysis of pathological features related to tumor size. $J$ Urol, 170, 2217-20

Golimbu M, Joshi P, Sperber A, et al (1986). Renal cell carcinoma: survival and prognostic factors. Urology, 27, 291-301.

Gudhjartsson T, Hardarson S, Petursdottir V, et al (2005). Histological subtyping and nuclear grading of renal cell carcinoma and their implications for survival: A retrospective nation-wide study of 629 patients. Eur Urol, 48, 593.

Gunes M, Gecit İ, Pirincci N, Taken K, Ceylan K (2012). Nature of lesions undergoing radical nephrectomy for renal cancer. Asian Pac J Cancer Prev, 13, 4431-3.

Jung EJ, Lee HJ, Kwak C, Ku JH, Moon KC (2009). Young age is independent prognostic factor for cancer-specific survival of low-stage clear cell renal cell carcinoma. Urology, 73, 137-41.

Kang HW, Seo SP, Kim WT, et al (2016). İmpact of young age at diagnosis on survival in patients with surgically treated renal cell carcinoma: a multicenter study. J Korean Med Sci, 31, 1976-82

Landis SH, Murray T, Bolden S, Wingo PA (1999). Cancer statistics. CA Cancer J Clin, 49, 8-31.

Licht MR (1995). Renal adenoma and oncocytoma. Semin Urol Oncol, 13, 262-6.

Lopez J, Moreno V, Garcia H, et al (2010). Renal cell carcinoma in young adults: a study of 130 cases and a review of previous series. Urol Int, 84, 292-300.

Mohsin R, Hashmi A, Sultan G, et al (2012). Renal tumors in young adults:a single-center experience from a developing country. J Urol, 9, 373-80

Remzi M, Katzenbeisser D, Waldert M, et al (2007). Renal tumour size measured radiologically before surgery is an unreliable variable for predicting histopathological features: benign tumours are not necessarily small. BJU Int, 99, 1002-6

Renshaw AA, Granter SR, Fletcher JA, et al (1999). Renal cell carcinomas in children and young adults: increased incidence of papillary architecture and unique subtypes. $\mathrm{Am}$ J Surg Pathol, 23, 795-802.

Sánchez-Ortiz RF, Rosser CJ, Madsen LT, Swanson DA, Wood CG (2004). Young age is an independent prognostic factor for survival of sporadic renal cell carcinoma. J Urol, 171, 2160-5.

Smith SJ, Bosniak MA, Megibow, et al (1989). Renal cell carcinoma: Earlier discovery and increased detection Radiology, 170, 699-3.

Taccoen X, Valeri A, Descotes JL, et al (2007). Renal cell carcinoma in adults 40 years old or less: young age is an independent prognostic factor for cancer-specific survival. Eur Urol, 51, 980-7.

Thompson RH, Ordonez MA, Iasonos A, et al (2008). Renal cell carcinoma in young and old patients- is there a difference? J Urol, 180, 1262-6.

Thompson RH, Kurta JM, Kaag M, et al (2009). Tumor size is associated with malignant potential in renal cell carcinoma cases. J Urol, 181, 2033-613.

Thrasher JB, Paulson DF (1993). Prognostic factors in renal cancer. Urol Clin North Am, 20, 247-62

Yıkılmaz TN, Baş O, Arık Aİ, Hızlı F, Başar H (2015). The relationship between histopathology and age factor in patients who were operated for renal masses. Turk J Urol, 41, 57-6.

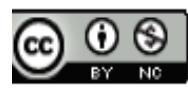

This work is licensed under a Creative Commons AttributionNon Commercial 4.0 International License. 